\title{
Efeito multiplicador do turismo na fronteira entre Brasil e Paraguai
}

\section{Multiplier effect of tourism on the border between Brazil and Paraguay}

\author{
Cristina Horst Pereira (PEREIRA. C. H.) ${ }^{*}$ \\ Patrícia Cristina Statella Martins (MARTINS, P. C. S.) ${ }^{* *}$ \\ José Roberto da Silva Lunas (LUNAS, J. R. da S.) \\ Juliana Maria de Aquino (AQUINO, J. M. de)
}

RESUMO - O Brasil tem $27 \%$ de seu território formado por faixa fronteiriça, e boa parte se encontra no Mato Grosso do Sul. Os municípios de Ponta Porã (Brasil) e Pedro Juan Caballero (Paraguai), desenvolveram o turismo de compras em decorrência de seu intenso comércio internacional. Com o objetivo de unir ambos os comércios em uma mesma ação, em 2012 houve a primeira edição do evento Black Friday na fronteira. Buscando entender o impacto do evento, propôs-se esta pesquisa, que objetiva a definição de quais seriam os multiplicadores econômicos para efeito do planejamento do turismo em Ponta Porã. Os objetivos secundários foram os de identificar os efeitos multiplicadores do turismo gerados em decorrência da realização do evento e apresentar um escopo de indicador para acompanhar o evento no futuro. $\mathrm{Na}$ metodologia se empregou a realização de pesquisa bibliográfica e aplicação de questionários. Nos

\footnotetext{
* Formação: Graduação em Turismo (Bacharelado) com ênfase em ambientes naturais; Especialização em Planejamento e Gestão Pública e Privada do Turismo e em Planejamento e Gestão Ambiental com ênfase em Avaliação Ambiental Estratégica e em Biologia da Conservação, obtidos junto à Universidade Estadual de Mato Grosso do Sul (UEMS). Ocupação profissional: Encarregada de Projetos na Fundação de Apoio à Pesquisa, ao Ensino e à Cultura de MS - FAPEMS. Dados para contato: Fundação de Apoio à Pesquisa, ao Ensino e à Cultura de MS (FAPEMS). Endereço: Rua Onofre Pereira de Matos, 1602 Bairro: Centro. CEP: 79.802-010 - Dourados - Mato Grosso do Sul (Brasil). Telefones: (067) 92632681/(067): 3422.2046. E-mail: cristinahorst@ gmail.com
}

** Formação: Graduação em Turismo pela Pontifícia Universidade Católica de Campinas (PUC Campinas). Mestrado em Geografia pela Universidade Federal de Mato Grosso do Sul (UFMS). Doutoranda em Geografia pela Universidade Federal da Grande Dourados. Ocupação profissional: Docente da Universidade Estadual de Mato Grosso do Sul (UEMS). Dados para contato: Universidade Estadual de Mato Grosso do Sul. - Rod. Dourados/Itahum Km 12. Caixa Postal 351 - Curso de Turismo. CEP: 79804-970 - Dourados - Mato Grosso do Sul (Brasil). Telefone: (67) 3902-2683. E-mail: martinspatricia@uems.br

\footnotetext{
Formação: Graduação em Administração de Empresas pela Universidade da Grande Dourados (UNIGRAN). Especialização em Administração de Marketing e em Comércio Exterior e Negócios Internacionais pela Universidade Católica Dom Bosco (UCDB). Mestrado e Doutorado em Desenvolvimento Sustentável pela Universidade de Brasília (UNB). Ocupação profissional: Professor e Pesquisador da Universidade Estadual de Mato Grosso do Sul - UEMS e Secretário Executivo da Fundação de Apoio à Pesquisa, ao Ensino e à Cultura de MS (FAPEMS). Dados para contato: Fundação de Apoio à Pesquisa, ao Ensino e à Cultura de MS (FAPEMS). Rua Onofre Pereira de Matos, 1602 Bairro: Centro. CEP: 79.802-010 - Dourados - Mato Grosso do Sul (Brasil). Telefone: (067) 3422-2046. E-mail: lunas@ fapems.org.br
}

***** Formação: Graduação em Ciências Econômicas, Mestrado em Economia e Doutorado em Ciências (Economia Aplicada), obtidos junto à Universidade de São Paulo (USP). Ocupação profissional: Professora e Pesquisadora da Universidade Federal da Grande Dourados (UFGD). Dados para contato: Universidade Federal da Grande Dourados (UFGD) - FACE - Faculdade de Administração, Ciências Contábeis e Economia. Rodovia Dourados-Itahum KM 12. Caixa Postal: 364. CEP: 79804-970 Dourados - Mato Grosso do Sul (Brasil). Telefone: (067) 3410-2040. E-mail: julianaaquino@ufgd.edu.br 
resultados identificaram-se os impactos econômicos diretos para a economia nacional, e concluiu-se que o melhor escopo de indicador encontrado foi a mensuração dos gastos realizados pelos visitantes diretamente no Brasil.

Palavras-chave: Efeito multiplicador, Turismo, Impacto econômico.

ABSTRACT - Brazil has $27 \%$ of your territory composed of border strip, much of this in Mato Grosso do Sul. The intense international trade between the cities of Ponta Porã (Brazil) and Pedro Juan Caballero (Paraguay) are the motivation to the development of shopping tourism. In 2012, the first edition of the event called "Black Friday" was created in order to maximize the shopping tourism in both countries. This research aimed to analyze the impact of this event and to define what should be the economic multiplier effects to plan the tourism at Brazilian side. The secondary objectives were to identify the tourism multiplier effects generated from the event and show a line guide to follow the event in the future. The methodology employed was literature research and questionnaires application. The results showed the direct economical impact in the national economy and the conclusion of this work was that the best indicator was the analysis of visitors' spending directly in Brazil.

Key words: Multiplier effect, Tourism, Economic Impact. 


\section{INTRODUÇÃO}

O Brasil, com sua continental dimensão, limita-se com nove países da América do Sul, e possui uma faixa de fronteira que representa $27 \%$ do território nacional, totalizando $15.719 \mathrm{~km}$, com 7.300km de fronteiras secas (BRASIL, 2010).

Parte desta "fronteira seca" está no Mato Grosso do Sul, que se limita com os países Bolívia e Paraguai. Merece destaque o município brasileiro de Ponta Porã e o paraguaio de Pedro Juan Caballero, por seu intenso comércio internacional, facilitado por sua condição de fronteira urbana com aproximadamente 13 quilômetros de extensão, conforme apresentado na Figura 1.

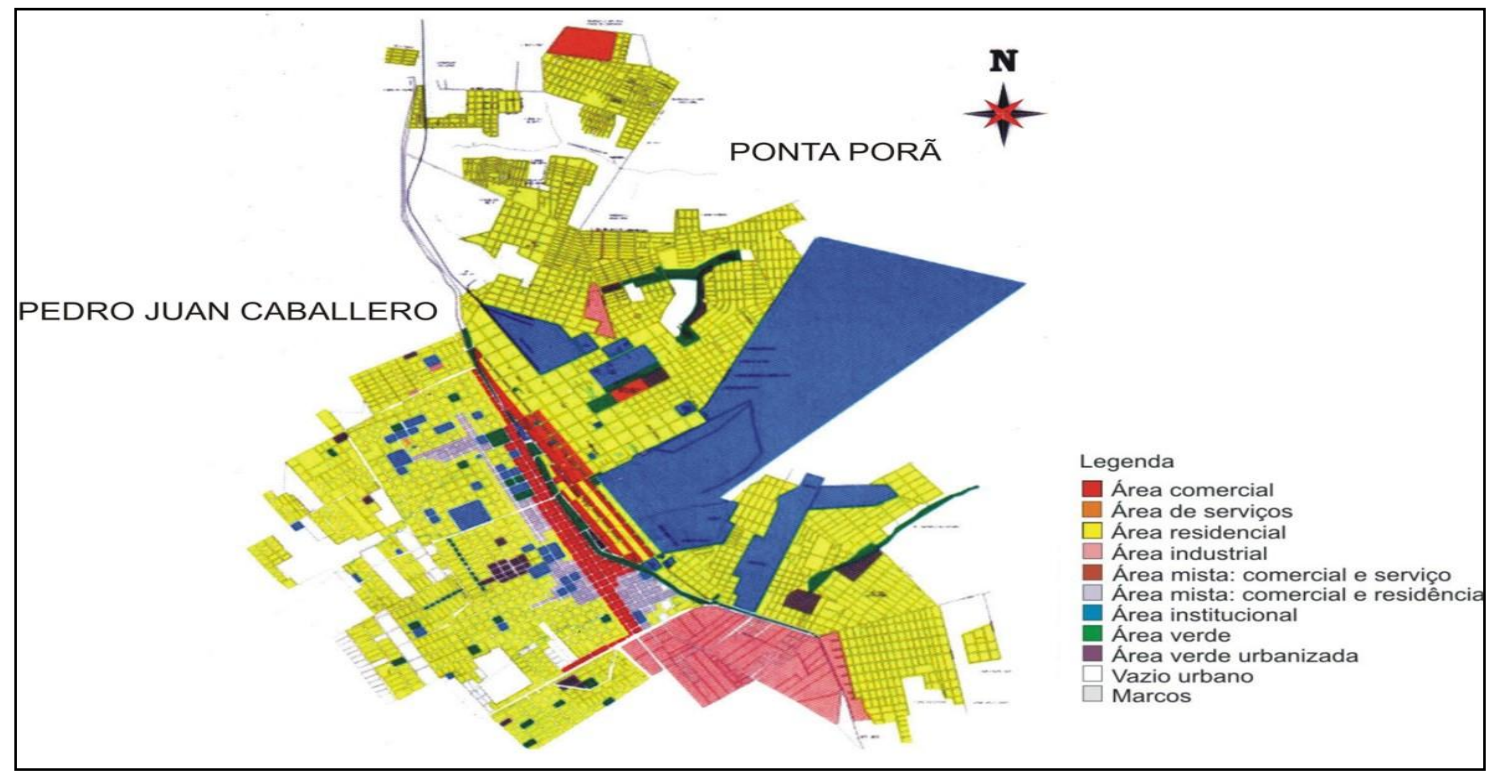

FIGURA 1 - PLANTAS DAS CIDADES-GÊMEAS, PEDRO JUAN CABALLERO E PONTA PORÃ, 2005.

Fonte: OLIVEIRA, 2010.

Tal característica a transforma em uma área dinâmica, pois entre as cidadesgêmeas não há pontes ou postos de identificação, e as cidades/países estão divididas apenas pelo canteiro central da Avenida Internacional. Neste sentido, o ir e vir torna-se constante, com uma espécie de permanente convite a transpor o limite estabelecido (MARTINS, 2007).

Apesar da riqueza histórica da região, palco do maior conflito deflagrado na América Latina, a chamada "Guerra do Paraguai” ou "Guerra da tríplice Aliança” (1865 
a 1870), o principal fator propulsor da atividade turística é outro: as compras (MARTINS, 2007).

A venda de produtos importados movimenta um grande fluxo de pessoas nesta fronteira, consolidando a atividade turística. Com isto, pode-se observar que a fronteira em si não é a principal atração para o turismo, mas sim as atividades que estão em seu entorno (MARTINS, 2007).

Diante a integração comercial, social e cultural entre os povos das duas cidades fronteiriças, no ano de 2012, por iniciativa da Câmara de Comércio e Indústria de Pedro Juan Caballero em conjunto com a Associação Comercial Empresarial de Ponta Porã ACEPP, idealizou-se a realização do evento Black Friday na fronteira, como medida pioneira de unir o comércio de ambos os países em torno de uma mesma ação (CÁMARA DE INDUSTRIA Y COMERCIO, 2013).

Em sua segunda edição em 2014, o evento é gerido por uma comissão específica formada por representantes dos empresários paraguaios e pela ACEPP, com auxílio do Ponta Porã Convention \& Visitors Bureau $(P P C \& V B)^{1}$ e apoio da Prefeitura Municipal de Ponta Porã, que juntos organizam as promoções no comércio que chegam a descontos de até 50\% do valor dos produtos (PREFEITURA MUNICIPAL DE PONTA POR Ã, 2013).

A primeira edição do evento, realizada em 2012, teve a duração de três dias. Conforme informações divulgadas pela Prefeitura Municipal de Ponta Porã (2013) no relatório de perfil socioeconômico, a edição inaugural reuniu um público total de aproximadamente 120 mil turistas brasileiros. O mesmo documento informa que segundo a Polícia Rodoviária Federal, durante os dias do evento, houve um fluxo estimado em 45 mil veículos com destino a esta região de fronteira. Ainda, conforme a Prefeitura, dados da Câmara de Comércio e Indústria de Pedro Juan Caballero estimam que o fluxo de vendas durante a primeira promoção do Black Friday na fronteira, tenha aumentado em cinco vezes o volume transacionado se comparado a um dia de comércio normal.

\footnotetext{
${ }^{1}$ Ponta Porã Convention \& Visitors Bureau (PPC\&VB) é uma instituição de apoio responsável pela "[...] organização de instituições que promovem o turismo e a receptividade de uma cidade ou localidade para convenções e visitação de eventos e atrações diversas" (PREFEITURA MUNCIPAL DE PONTA PORÃ, 2013, p. 13).
} 
Nas estimativas da Prefeitura Municipal de Ponta Porã (2013), os gastos gerais durante o evento foram de aproximadamente de U\$S 80 milhões. Ainda consta na mesma fonte que estes gastos distribuíram-se entre estabelecimentos de alimentação, hospedagem e comércio em geral, com aproximadamente U\$S 24 milhões gastos no Brasil e U\$S 56 milhões gastos no Paraguai. Ainda, segundo a mesma fonte, em 2013 a expectativa era de vender U\$S 120 milhões, com um fluxo aproximado de 150 mil pessoas (PREFEITURA MUNICIPAL DE PONTA PORÃ, 2013).

Diante da expectativa de aumento do fluxo de visitantes durante a edição do Black Friday 2013, o PPC\&VB solicitou o auxílio da Universidade Estadual de Mato Grosso do Sul - UEMS, para efetuar uma pesquisa durante a realização do evento.

Visto as peculiares condições de fronteira, os envolvidos na organização do evento constataram que os gastos em compras aconteceram em proporções maiores no Paraguai do que no Brasil. Por essa razão, buscaram abordar quais seriam os efeitos multiplicadores para fins de planejamento do turismo no município de Ponta Porã.

Com uma análise científica, a partir da estimativa realizada em um período de grande fluxo de visitantes, almeja-se que os governantes percebam a importância econômica da atividade turística de compras na região, o que poderia estimular o trabalho em prol da capacitação e profissionalização do turismo fronteiriço. Para tanto, como objetivos secundários, elegeu-se os seguintes itens: identificar quais os possíveis efeitos multiplicadores do turismo gerados em decorrência da realização do Black Friday em Ponta Porã; e indicar o escopo de indicador que pudesse permitir acompanhar o evento nos próximos anos.

Para atender aos objetivos gerais, optou-se por identificar, a partir de pesquisa bibliográfica, os possíveis impactos econômicos gerados pelo turismo, sobretudo dos efeitos multiplicadores que poderiam ocorrer ou foram fortalecidos em decorrência da realização da edição do Black Friday 2013. Na busca pela indicação de um escopo de indicador que permitisse acompanhar o evento nos próximos anos, adotou-se como método de pesquisa a aplicação de questionários junto aos visitantes.

Os dados foram levantados durante o período de realização do evento "Black Friday 2013", durante os dias 20 a 22 de setembro e aconteceu nas cinco lojas de maior fluxo de visitantes na fronteira: Popai, Studio Center, Alta Vista Shopping, Shopping China e Fortis Atacado, todas localizadas em Pedro Juan Caballero. 
Anterior ao período de aplicação realizou-se um pré-teste objetivando verificar se as variáveis definidas eram adequadas para responder aos objetivos do estudo, conforme orientação de Dencker (2000). Após as correções necessárias e realização do treinamento dos aplicadores, teve início o trabalho de campo.

$\mathrm{Na}$ pesquisa, empregou-se o método de amostragem por seleção aleatória, respeitando um intervalo de seleção de 10 indivíduos. Devido à diferença de fluxo nos dias de realização da pesquisa, optou-se pela aplicação estratificada da amostra, sendo 44\% dos questionários aplicados no dia 20, no período das 9 às 15 horas; $33 \%$ no dia 21 no mesmo período e $23 \%$ no dia 22 das 8 às 12 horas. Além disso, considerando a diferença de fluxo de visitantes entre os empreendimentos, optou-se por sua estratificação, onde um total de $45 \%$ dos questionários foram aplicados junto aos visitantes do empreendimento de maior fluxo, e o restante dividido igualitariamente entre os demais.

A pesquisa alcançou $10 \%$ dos visitantes presentes nos locais da pesquisa durante os dias do evento. Sendo o cálculo da amostra junto à seleção aleatória importantes para o aumento do grau de confiabilidade nas inferências sobre a população, trabalhou-se com grau de significância (estimativa de erro) de 5\%, e por consequência, grau de confiança de 95\% (BARBETTA, 2001). No total foram 627 questionários, sendo que destes, 577 foram respondidos, 22 foram recusados e 28 ficaram em branco.

Ressalta-se que realização do presente trabalho traz uma importante contribuição para a literatura, principalmente a respeito do estudo do turismo de fronteira sob a perspectiva econômica na divisa entre Ponta Porã e Pedro Juan Caballero, por tratar-se de um campo exploratório relativamente novo, e com poucas publicações disponíveis que abordam a temática na região.

\section{CARACTERIZAÇÃO DA REGIÃO EM ESTUDO}

A vocação da fronteira entre Ponta Porã e Pedro Juan Caballero para atividades relacionadas às compras remonta à época de sua fundação, pois em virtude de sua localização geográfica, no fim do século XIX, a região servia como ponto de parada

para os mercadores que transportavam erva-mate (MARTINS, 2007). O 
desenvolvimento da região continuou relacionado à produção e exploração da erva mate, que em meados dos anos 1960, possibilitou o desenvolvimento do comércio de importados (PREFEITURA MUNCIPAL DE PONTA PORÃ, 2013).

Com o passar do tempo, as relações comerciais foram aprimoradas e o fortalecimento do comércio permite a atual troca de clientes, pois como afirmou Cunha (2010), em locais de fronteira é comum a busca de produtos e serviços no país vizinho, em virtude principalmente das condições e preços oferecidos. Durante a realização de eventos promocionais, evidencia-se que os brasileiros, (turistas e moradores) em geral buscam na cidade vizinha uma infinidade de produtos, muitos deles produzidos no Brasil e que, em virtude do tratamento que as mercadorias nacionais recebem para exportação, apresentam preços mais atrativos no exterior. Em contrapartida, é possível constatar que em regra, como já indicado por Lamberti, Martins e Oliveira em 2006, os paraguaios buscam no Brasil bens e produtos que correspondem ao seu padrão de consumo, motivados principalmente pelas formas de pagamento (sistema de crédito), em especial o das vendas a prazo.

A intensificação do comércio internacional impulsionou o desenvolvimento da infraestrutura turística e de apoio das cidades-gêmeas, que estão voltadas tanto para o atendimento da população quanto à recepção dos visitantes.

Segundo dados da Secretaria de Indústria, Comércio e Turismo de Ponta Porã, um levantamento realizado em 2012 apontava que existiam, à época, 23 instalações hoteleiras, 34 restaurantes e pizzarias e 6 agências de turismo em funcionamento distribuídas entre os dois países, com previsão de expansão destes números para o ano de 2013; além de um calendário de eventos bastante movimentado, que em sua infraestrutura de apoio estava contando com um centro de convenções do lado brasileiro e diversos espaços destinados a realização de eventos de ambos os lados fronteiriços (PREFEITURA MUNICIPAL DE PONTA PORÃ, 2013).

Ao comparar o Brasil e o Paraguai, em aspectos socioeconômicos verificou-se haver certa discrepância comprovada pela apresentação de informações como as do Índice de Desenvolvimento Humano - $\mathrm{IDH}^{2}$, que em seus desdobramentos do ano de 2011 apresentou os seguintes valores para o Brasil: IDH: 0,718; esperança de vida: 73,5

\footnotetext{
${ }^{2}$ IDH: Medida resumida do progresso a longo prazo em três dimensões básicas do desenvolvimento humano: renda, educação e saúde. 2013. Disponível em: <http://www.pnud.org.br/IDH/IDH.aspx?indiceAccordion=0\&li=li_IDH>. Acesso em: 29/11/2013.
} 
anos e escolaridade: 7,2 anos; e os seguintes valores para o Paraguai: IDH: 0,665; esperança de vida: 72,5 e escolaridade: 7,7 (PNUD, 2011).

Quando a comparação entre as nações se dá em âmbito municipal, as diferenças entre os países acentuam-se ainda mais, principalmente quando se inclui a questão demográfica, pois em extensão territorial, Ponta Porã possui uma área de 5.330,448 km² (IBGE-1, 2013) com densidade populacional de 15,57 habitantes por $\mathrm{km}^{2}$ e Pedro Juan Caballero de 5.259,60 km² (SEBRAE, 2013) e densidade de 17,86 habitantes por km².

Na avaliação do índice de Gini $^{3}$ apurado em 2011, Ponta Porã possuía um nível de desigualdade de 0,604, mantendo-se superior aos índices brasileiros $(0,526)$ e estadual $(0,509)$ (IBGE - 2, 2013). Já informações referentes a tal índice para o país vizinho apontaram um valor inferior: 0,524 (MINISTERIO DE ASUNTOS EXTERIORES, 2013). Estas informações demonstram que a desigualdade social, representada pela distribuição de renda, é maior no município brasileiro.

O município paraguaio de Pedro Juan Caballero (PJC) é a atual capital jurídica e legislativa do Departamento de Amambay, localizado a 487 km de Asunción (capital do Paraguai), que compõe um dos maiores centros urbanos do país, com aproximadamente de 90 mil habitantes (PREFEITURA MUNICIPAL DE PONTA PORÃ, 2013). Já, do lado brasileiro, o município de Ponta Porã, distante 290 km de Campo Grande (capital do estado de Mato Grosso do Sul), conta com uma população estimada em aproximadamente 83 mil habitantes (IBGE-1, 2013).

No entanto, uma fragilidade que se estende aos dois lados da fronteira está relacionada ao planejamento urbano, em que assim como outros serviços públicos, se ignora a situação de conurbação urbana (LAMBERTI, MARTINS, OLIVEIRA, 2006). Lembrando, como afirma Nascimento et al (2013), que o planejamento do turismo deve ser um processo contínuo que necessita manter-se constantemente em avaliação, para que possa atuar como agente de desenvolvimento local.

A troca entre os países, Brasil e Paraguai, também é percebida na relação existente entre a força de trabalho de ambos. Devido à fluidez dos deslocamentos, o emprego de brasileiros no Paraguai e vice-versa é comum, fato que expressa a flexibilização da oferta de trabalho, e apresenta-se como característica do estágio

\footnotetext{
${ }^{3}$ Índice de Gini - mede a distribuição da renda de determinada localidade, cujo valor varia de zero (perfeita igualdade, onde todos possuem a mesma renda) até um (a desigualdade máxima). Para maiores detalhes consultar IPEA (2013).
} 
produtivo capitalista. No entanto, tal flexibilidade (que amplia a oferta da mão de obra) pode resultar na queda dos níveis salariais e eventual comprometimento do poder de negociação e compra dos trabalhadores (LAMBERTI, MARTINS, OLIVEIRA, 2006).

\section{REFERENCIAL TEÓRICO}

Segundo Rabahy (2003) graças ao pioneirismo de Tomas Cook em organização de viagens, e aos fomentos empresariais de Cesar Ritz no setor hoteleiro, Karl Baedecker com os guias de turismo, George Pullman e o turismo ferroviário, dentre outros, o turismo pode se firmar como atividade econômica a partir da metade do século XIX.

Genericamente, Lage e Milone (2000) definem a atividade turística como o deslocamento humano voluntário, que envolve a produção de componentes ou recursos relacionados a transporte, hospedagem, alimentação, lazer e/ou outros, para atender às necessidades dos indivíduos de diferentes sociedades e culturas.

Mais diretamente, Tribe (2003) define o turismo como visita (movimento temporário para fora do habitual local de moradia e trabalho) que envolva ao menos um pernoite, com a finalidade de lazer, férias ou trabalho.

Dentro das atividades desenvolvidas pelo turismo, Panosso Netto e Ansarah (2009) apresentam uma classificação que as dividem em 119 segmentos, levando em consideração alguns aspectos como: idade; economia; tempo de permanência; meios de transporte; motivação da viagem; tipo de grupo; aspecto cultural, entre outros. Dentre os segmentos apresentados encontra-se o turismo de compras.

Tanto o Ministério do Turismo (BRASIL, 2006) quanto Vaz (1999) não possuem uma definição para o Turismo de Compras. Abordam as compras como uma das atividades realizadas pelas pessoas que viajam com fins comerciais ou de negócios. Porém em áreas fronteiriças como Pedro Juan Caballero as compras também são para consumo pessoal e nem sempre baseadas em vantagens com relação ao preço. Para Verbeke-Jansen (2002) a experiência vai além dos aspectos econômicos gerados pela atividade e que tradicionalmente são os mais ressaltados. As pessoas além de realizarem algo fora de sua rotina habitual sentem prazer em comprar. 
O turismo de compras na fronteira de Ponta Porã e Pedro Juan Caballero, ocorre em virtude do fenômeno mencionado por Cunha (2010), que aponta que residentes e visitantes de regiões fronteiriças adquirem produtos e serviços do outro lado da fronteira, em virtude de melhores condições e preços de produtos ou serviços. Por não haver limitação de circulação, o fluxo é constante, proporcionando ao país vizinho a riqueza que poderia ser gerada em seu local de residência por meio de despesas de importação (CUNHA, 2010).

A importância da atividade turística, sob a perspectiva econômica, se dá não pela motivação da viagem em si, mas sim pelas consequências não intencionadas (implícitas) no ato de viajar (BARBOSA; MARTELOTTE; ZOUAIN; 2006). Segundo o raciocínio de Barbosa (2002), a realização da viagem depende diretamente da existência de recursos financeiros, que via de regra, são adquiridos por meio do trabalho e poupança do viajante. A partir desta premissa, denota-se que "[...] numa sociedade onde existe a cultura do turismo, há permanentemente oferta de recursos derivados da poupança dos que estão esperando o momento de transformá-los em dispêndio de viagem, e uma intensa movimentação das atividades produtivas derivadas do turismo" (BARBOSA, 2002, p. 2).

Os valores transacionados que decorrem da atividade turística são interpretados como uma injeção de recursos via aumento da demanda na economia local, fato que exige um complexo estudo para sua estimação, vista a gama de produtos e serviços envolvidos na atividade (BARBOSA; MARTELOTTE; ZOUAIN; 2006).

Além dos gastos realizados pelos turistas, há que se considerarem outras variáveis que complementam a avaliação dos impactos econômicos, que são: efeitos indiretos e induzidos, vazamento dos gastos locais e o deslocamento da mão de obra e custos de oportunidade (COOPER et al, 2001).

Os efeitos indiretos e induzidos incluem as compras e novos negócios que surgem em função da renda do turismo; os vazamentos referem-se às compras de produtos importados para atender às necessidades dos visitantes e o deslocamento considera a vinda de trabalhadores de outros setores para atuar no turismo, além de poupanças e impostos (TRIBE, 2003).

É importante ressaltar que, por vezes, as análises econômicas que se referem ao turismo o avaliam por uma perspectiva unilateral, que ressalta os impactos positivos e 
desconsidera os negativos, como: sazonalidade, trabalhos temporários, inflação, importações, entre outros (BARBOSA; MARTELOTTE; ZOUAIN; 2006).

Em síntese, no estudo dos impactos econômicos do turismo se verifica o fluxo de gastos associados à atividade, como gastos diretos, impostos, renda e geração de empregos, além de revelar a inter-relação entre turismo e economia, fornecendo subsídios para possíveis mudanças na economia em decorrência de outras ações (BARBOSA; MARTELOTTE; ZOUAIN; 2006). Estes impactos são frequentemente ignorados pelo poder público para fins de planejamento, provocando a perda de oportunidades importantes para a potencialização das atividades do turismo. Considerando a dinamicidade da atividade turística, ressalta-se que o planejamento da atividade é tão essencial para garantia do desenvolvimento local, quanto a sua reavaliação e adequação para atender às exigências impostas pela globalização mundial (NASCIMENTO et al, 2013).

Uma alternativa eficaz para a captação e/ou estimação dos efeitos secundários desencadeados pelo turismo é o emprego do efeito multiplicador. Segundo definição de Lemos (2005), o efeito multiplicador está relacionado ao impacto inicial dos gastos, que atuam como um catalisador de demanda e de emprego. Neste sentido, Lage e Milone (1992), tratam este efeito como sendo o fenômeno pelo qual o aumento ou diminuição dos gastos totais repercutirá no aumento ou diminuição mais do que proporcional do nível de equilíbrio da renda nacional. Neste sentido, quanto maior o consumo, maior o efeito multiplicador, e maior a propensão ao acréscimo da renda nacional, implicando em um maior desenvolvimento econômico (BORATTI; ROCHA, 2008).

Boratti e Rocha (2008) informam que o efeito multiplicador pode ser subdividido nas seguintes categorias:

- efeitos diretos: gastos realizados pelos visitantes nos locais fornecedores de bens e serviços turísticos. No entanto, parte deste valor destina-se aos gastos com importações para o suprimento de tais serviços. Dessa maneira, via de regra, os impactos diretos dos gastos tendem a ser menores que o próprio gasto, a menos que a economia local consiga produzir e satisfazer todas as necessidades dos turistas;

- efeitos indiretos: entrada de recursos mediante investimentos diretos e consumo, realizados pelos equipamentos e prestadores de serviços turísticos a fim de atender o aumento da demanda; 
- efeitos induzidos: refere-se à renda gerada a partir da dinamização dos fatores produtivos que resultam no aumento do consumo, poupança, investimentos e tecnologia, ocasionada em função do turismo que se desdobram em outras atividades econômicas. Ou seja, são as despesas realizadas pelos agentes que receberam o dinheiro dos prestadores de serviços turísticos e similares.

A complexidade na mensuração dos impactos econômicos decorrentes da atividade turística destaca a necessidade de utilização de multiplicadores econômicos específicos.

Para Fletcher e Archer ${ }^{4}$ apud Barbosa (2002), o multiplicador turístico diz respeito às taxas calculadas em função de alterações identificadas nos gastos turísticos e nas variáveis chaves de produção (renda, emprego, receitas de governo). No entanto, um empecilho para o emprego prático deste multiplicador está na dificuldade de sua identificação, pela falta de dados a respeito do ingresso de pagamentos provenientes da atividade turística, em relação à incidência de outras causas econômicas (RABAHY, 2003). Neste contexto, a estimação dos gastos dos turistas torna-se um bom indicador para captação dos efeitos diretos da importância do turismo na economia local de determinado destino (BARBOSA; MARTELOTTE; ZOUAIN; 2006).

As pesquisas em torno do multiplicador do turismo buscam a avaliação do impacto sobre as rendas, a produção e o emprego, seja na dimensão nacional, regional ou local. Essas informações são importantes para orientar os governos na avaliação da contribuição do turismo para o desenvolvimento econômico. Assim, torna-se possível enumerar os principais multiplicadores para a análise de impacto como sendo o de produção, de renda, de emprego e o de receita do governo (TRIBE, 2003); que Lage e Milone (1992) classificam como multiplicadores específicos do turismo, acrescidos ao multiplicador de renda, o item transação.

Tais ferramentas possibilitam a quantificação das variações dos níveis de renda, emprego, produtos, ou entrada e saída de divisas ocorridas em função das variações dos gastos diretos dos turistas. Ressalta-se que, a magnitude do efeito multiplicador apresenta uma dependência direta das relações intersetoriais da economia, que por sua vez dependem de seu tamanho e grau de desenvolvimento (LAGE; MILONE, 1992).

\footnotetext{
${ }^{4}$ FLETCHER, J. E.; ARCHER, B. H. The development and aplication of multiplier analysis. In: COOPER, C. P. Progress in Tourism, Recreation and Hospitality Management. London: Belhaven, 1991. v. 1.
} 
Lemos (2005) enumera os seguintes elementos observados no turismo como fenômeno econômico: realização de gastos por parte das pessoas quando viajam, consumindo serviços e produtos fora de seu local de residência; recursos financeiros que financiam a realização dos gastos turísticos; operadoras e agências de turismo que intermediam as negociações entre oferta e demanda; locais dotados de atratividade; residentes do local receptor e seu relacionamento com os turistas e os benefícios econômicos obtidos; componentes da oferta, que são os planejadores e elaboradores do produto turístico (empresas privadas e órgãos públicos); e empresas que atuam direta e indiretamente no turismo.

O desenvolvimento da atividade turística desencadeia uma série de impactos econômicos, tantos positivos quantos negativos. Na perspectiva dos efeitos positivos, Cooper et al (2001) os sintetiza como sendo a injeção de demanda na economia receptora e o efeito multiplicador. Ruschmann (2001) os detalha com subdivisões que incluem:

- efeitos diretos: aumento da renda nacional / regional / local;

- efeitos secundários: absorção da renda dos estrangeiros em outros setores da economia;

- efeitos terciários: investimentos estimulados pelo turismo, como a geração de empregos e investimento em infraestrutura básica e específica.

Além desses, Ruschmann (2001) ainda cita Palomo $(1979)^{5}$ e seus efeitos positivos no nível social da comunidade receptora, que segundo esta ótica, envolve a melhoria da renda dos habitantes, o aumento do nível de profissionalização, a expansão do setor da construção, a alteração da estrutura econômica e social local, maior industrialização e a atração de mão de obra.

A respeito dos impactos econômicos negativos, Cooper et al (2001) menciona dois itens principais: o custo de oportunidade na utilização de recursos escassos, representado pelo comprometimento de recursos que poderiam ser alocados em outras finalidades para fins de turismo; e o efeito deslocamento, que ocorre quando o desenvolvimento do turismo se dá à custa de outros setores (custo oportunidade de desenvolvimento). Ruschmann (2001) sintetiza tais impactos em 4 itens principais: custos de oportunidade; o fato de a dependência excessiva do turismo poder ocasionar

\footnotetext{
${ }^{5}$ PALOMO, M. F. Economia turística. Tese de Doutorado. Madrid: Ed. Imansa, 1979.
} 
um colapso econômico em virtude da instabilidade da demanda; a inflação e especulação imobiliária; e a sazonalidade da atividade.

\section{RESULTADOS}

Constatou-se que as expectativas em relação ao número de visitantes e a movimentação financeira da edição do Black Friday na fronteira em 2013, mantiveramse abaixo das expectativas. Segundo informações levantadas junto ao PPC\&VB, o evento contou com um total de 50 mil compradores contra a previsão de 180 mil, sendo 25 mil visitantes e 25 mil residentes em Ponta Porã ou Pedro Juan Caballero (CARPES, 2013). A estimativa geral de vendas em 2013 ficou em torno de U\$S 56 milhões, número inferior à metade do previsto anteriormente, que era de U\$S 120 milhões, sendo U\$S 14 milhões movimentados no Brasil e o restante, U\$S 42 milhões, movimentado no Paraguai (CARPES, 2013).

Rabahy (2003) afirma, com base em estudos realizados pela FIPE - Fundação Instituto de Pesquisas Econômicas, que o estimador de renda dos gastos dos visitantes estrangeiros no Brasil situava-se ao redor de 2,85. A aplicação deste dado empírico em caráter especulativo; considerando a injeção direta de um valor de U\$14 milhões na economia nacional em função do Black Friday de 2014; possibilita a afirmação de que o efeito multiplicador em função da realização do evento se desdobrou em um valor aproximado de U\$40 milhões na economia brasileira local.

Em relação à execução, quando os visitantes foram questionados se os preços praticados pelas empresas participantes do evento se mantiveram dentro de suas expectativas, 68,6\% respondeu que sim. Dos que responderam negativamente, as informações se diluíram entre reclamações a respeito do preço dos produtos, que se desdobraram em queixas que se referiam ao desconto real, ao fato dos preços não diferirem do cotidiano e de muitos itens não estarem em promoção.

Lemos (2005), pontua que os principais elementos que caracterizam o turismo como fenômeno econômico são resultantes do ato de viajar e consumir, ainda que de forma temporária , bens e serviços de outras localidades. Para maior detalhamento das características do agente que origina a ação turística, buscou-se informações que 
pudessem subsidiar a criação, ainda que de forma genérica, de um perfil econômico do visitante.

Tal perfil apurou além de informações básicas (sexo, idade, estado civil, entre outros) elementos que pudessem demonstrar a condição econômica do visitante, por meio de dados como: escolaridade, profissão, meio de transporte utilizado, tempo de permanência, local de hospedagem, pretensão de gastos com alimentação e compras, entre outros. Objetivou-se a estimação da renda salarial dos entrevistados com base no piso salarial das profissões listadas, correlacionado ao grau de instrução das pessoas. No entanto, problemas na coleta dos dados impossibilitaram a utilização de ambas questões para este trabalho, assim como impediu a elaboração do perfil econômico almejado. Desta forma, para tal questão demonstram-se resultados não conclusivos, o que indica a necessidade de ajustes na etapa da coleta das informações, a fim de tornar os resultados válidos para análises posteriores.

Como mencionado anteriormente por Barbosa, Martelotte e Zouain (2006), o fato da estimação dos gastos dos visitantes ser um bom indicador para a captação dos efeitos diretos da importância do turismo para determinada localidade, levou à tentativa de estimação dos gastos dos turistas durante a realização do evento, com foco para os gastos que de alguma forma pudessem ser revertidos em algum multiplicador direto para o Brasil. Desta forma, levantou-se informações a respeito do local de residência, forma de transporte, local de abastecimento, hospedagem, estimativa de gasto com alimentação e com compras efetuados pelos visitantes durante o evento e forma de pagamento adotado.

Apurou-se que $51 \%$ dos entrevistados eram residentes de outras localidades do estado de Mato Grosso do Sul e outros 28,6\% residentes em Ponta Porã ou Pedro Juan Caballero.

Dos visitantes não residentes, 55,5\% voltavam à sua residência no mesmo dia, alegando a pouca distância ou que a motivação única da viagem foi a de compras. Dos que afirmam permanecer mais tempo, 20,5\% apenas pernoitavam, 14,7\% permaneciam 2 dias, e o restante, 9,3\% permanecendo 3 dias ou mais. Na concepção de Cunha (2010), estes viajantes não perdem sua natureza de turistas/visitantes em razão da distância entre o centro de produção e consumo, ou seja, o local de residência e de visita, nem mesmo pelo fato de percorrerem habitualmente uma distância mínima fixada arbitrariamente. 
Ainda assim, a Organização Mundial do Turismo (OMT) considera turista apenas as pessoas que se deslocaram para lugares diferentes de seu entorno habitual (ORGANIZAÇÃO MUNDIAL DO TURISMO, 2001).

Destaca-se que dentre todos os entrevistados não residentes, 51,5\% afirmou ter viajado especificamente para a realização de compras durante o evento Black Friday, e que $31,7 \%$ informou ter viajado para a realização de compras, independentemente da realização do evento. Esta informação demonstra que em decorrência da realização do evento, houve a duplicação do número de visitantes esperados em relação a um dia normal de vendas.

Dentre os visitantes que mencionaram pernoitar, apenas $44,9 \%$ utilizaram hotéis como meio de hospedagem; e destes 33,2\% informaram estarem hospedados do lado brasileiro, 7,2\% do lado paraguaio, e o restante dos entrevistados não respondeu.

Dos entrevistados não residentes em Ponta Porã ou Pedro Juan Caballero, 94,9\% se deslocaram de carro. Dentre os entrevistados que mencionaram pretender abastecer seus veículos, $58 \%$ pretendiam o fazer no Brasil, $18 \%$ no Paraguai e $24 \%$ não o sabiam ou não responderam.

Quando questionados a respeito da estimativa de gastos pretendida durante o evento, 27,6\% informaram manter-se na faixa entre $\mathrm{R} \$ 100$ a 500 reais, $22,4 \%$ entre $\mathrm{R} \$$ 501 e 1.000 reais, $26 \%$ entre $R \$ 1.001$ a 2.000 reais e $24 \%$ acima de $R \$ 2.000$ reais. Vale lembrar que o limite da cota para produtos importados por via terrestre era de US\$ 300 (ou equivalente em outra moeda) ${ }^{6}$, e que a fim de não constranger o visitante, nem mesmo estimular a sua não participação na pesquisa, não foi questionado se, no caso dos brasileiros, havia a intenção de realizar a declaração de compra e mesmo o pagamento de impostos, caso necessário, junto à Receita Federal.

Conforme $28 \%$ dos entrevistados, os gastos individuais com alimentação giraram em torno de $\mathrm{R} \$ 21,00$ a 40,00 reais. No entanto, houve um empate entre os valores que iam até $R \$ 20,00$ e os que variavam de $R \$ 41,00$ a 60,00 apresentando um percentual de $22,3 \%$ cada.

Outro aspecto considerado interessante é o de que estes visitantes, $74 \%$ no total, costumavam fazer as compras em dinheiro, isentando o recolhimento da cobrança do

\footnotetext{
${ }^{6}$ Fonte: RECEITA FEDERAL. 2014. Disponível em:

<http://www.receita.fazenda.gov.br/aduana/viajantes/viajantechegbrasilsaber.htm>. Acesso em: 06/01/2014.
} 
IOF (Imposto sobre Operações de Crédito, Câmbios e Seguros), que incidia sobre as transações financeiras internacionais. A tendência foi a de que as compras em dinheiro viessem a ser intensificadas, uma vez que em dezembro de 2013 o Governo Federal estendeu a cobrança do imposto para além dos gastos com cartão de crédito, incluindo a taxação dos pagamentos efetuados com cartão de débito, saques de moeda estrangeira no exterior, cheques de viagem e carregamento de cartões pré-pagos com moeda estrangeira (BRASIL, 2013).

Um relevante resultado é o fato de que o detalhamento da pesquisa iniciada neste trabalho pode vir a subsidiar a criação de um modelo teorométrico para fins de estimação dos efeitos multiplicadores econômicos do turismo na fronteira. Tal modelo consiste na junção de conhecimentos científicos do turismo fundamentados na matemática e estatística; ambos componentes da econometria, para realizar consistentes previsões para o turismo (RABAHY,1990).

Tal ação pode tornar-se possível pelo fato dos modelos de previsão turística (teorométricos), estarem comumente relacionados às variáveis da oferta e da demanda, que têm como principais representantes algumas informações já levantadas por esta pesquisa, como as distâncias geográficas percorridas, o custo e tempo de viagem, o grau de relação político, cultural e econômico em fronteiras internacionais, e informações qualitativas fornecidas pelo processo de formação histórica dos países (RABAHY, 1990).

Ressalte-se que a construção de modelos como o mencionado, permitem análises mais realistas do turismo e seus desdobramentos, fundamentando melhor as decisões políticas e econômicas para o setor.

\section{CONSIDERAÇÕES FINAIS}

A condição de fronteira transforma a estimação de multiplicadores para o turismo em um verdadeiro desafio; no caso estudado, os visitantes eram originários de um país e efetuavam a maior parte dos gastos no país vizinho. Estimar os gastos diretos e mesmo os multiplicadores que se desdobram na economia nacional torna-se uma tarefa com grau acentuado de complexidade. 
No entanto, a realização deste trabalho possibilitou identificar alguns itens que geraram impactos econômicos diretos de maior relevância, resultantes da realização do Black Friday da fronteira em 2013. Estes itens podem vir a se desdobrar em efeitos multiplicadores do gasto turístico para Ponta Porã, como o fato dos visitantes deslocarem-se em sua grande maioria de carro e abastecerem e se hospedarem no Brasil. Em menor grau de importância, se pode mencionar o recolhimento de IOF e o pagamento dos impostos que incidem sobre o valor que excede às cotas dos produtos declarados.

Como afirma Cooper et al (2001), é válido estabelecer a importância dos gastos do turismo para uma economia, para subsidiar as decisões futuras a serem tomadas pelos formuladores de políticas e planejadores. Nesta perspectiva, aponta-se o gasto direto do turista no Brasil durante a realização do evento como um importante escopo de indicador para o acompanhamento da realização do Black Friday em suas próximas edições.

Neste sentido, a estimação do desdobramento financeiro do gasto do visitante na economia local, conforme dado especulativo apresentado por meio das considerações de Rabahy (2003), permite a identificação e o acompanhamento dos benefícios diretos para a economia local com a realização do evento. A partir disso, torna-se possível avaliar os multiplicadores econômicos locais, mensurando sua importância para a economia local, com vistas ao aprimoramento do evento.

Devido à complexidade de mensuração dos efeitos multiplicadores, torna-se importante a continuidade do estudo de suas causas, impactos e desdobramentos. Para tanto, recomenda-se que em edições posteriores sejam mantidas as indagações determinantes para a constatação das ações geradoras do efeito multiplicador em suas dimensões diretas e indiretas. Tais indagações envolvem questões sobre perfil do turista (local de origem, meio de transporte, tempo de permanência, hospedagem) e seus gastos (estimativa de gasto com compras e alimentação, forma de pagamento, local de abastecimento, entre outros).

Por meio da mensuração dos gastos é possível comprovar a importância econômica do turismo na economia local (BARBOSA; MARTELOTTE; ZOUAIN; 2006), e a estimação de seu perfil poderá trazer indícios reais do desdobramento desses gastos. Juntos, esses dados podem compor um modelo teorométrico que possibilita a 
auferição de estimativas reais do desdobramento de tais multiplicadores, a fim de comprovar a importância econômica do turismo de compras para a fronteira.

Cabe ressaltar que a criação de um modelo teorométrico exige esforços acadêmicos direcionados e multidisciplinares. Pelo fato destas previsões fundamentarem-se em dados estatísticos, a qualidade destes torna-se de importância acentuada, uma vez que grande parte dos trabalhos do turismo que empregam a teorometria buscam a criação de informações e projeções para o turismo, almejando a redução da margem de erro das previsões e fundamentação as decisões políticas locais (RABAHY, 1990).

Em tempo, a delineação do perfil pode ser adequada em uma próxima edição da pesquisa segundo indicação de Dencker (2000); onde a estimação da classe econômica dos visitantes se dá por questões também indiretas, que informem mais a respeito do tipo de vida do que sobre a visita ao evento. Seguindo o mesmo raciocínio, Rabahy (1990) afirma que o resultado de algumas variáveis, como a renda, podem ser adotados como síntese de outros impactos como nível cultural e grau de escolaridade. Dessa maneira, a criação de um sistema de classificação dos visitantes poderia permitir análises mais finas, assim como comparações que possam vir a subsidiar a decisão dos atores interessados.

Porém, um modelo de questionário como esse pode tornar-se extenso, e vir a dificultar a participação dos visitantes. É importante que os atores interessados elejam as prioridades de informações a serem coletadas de forma a não comprometer a realização da pesquisa.

Vale lembrar, conforme menção de Rabahy (2003), que a identificação do efeito gerado pelos multiplicadores é uma tarefa complexa, pela falta de dados relativos à atividade turística em detrimento a outras causas econômicas. Neste sentido, a pesquisa apresentada visou uma iniciativa de pesquisa nesta área, com a idealização de um banco de dados inicial.

Por fim, ressalta-se que o presente trabalho apresenta-se como um estudo pioneiro na região fronteiriça de Ponta Porã e Pedro Juan Caballero, tanto no que se refere aos efeitos multiplicadores do turismo de compras, como quanto à criação de um banco de dados para o acompanhamento do evento Black Friday na fronteira. Nesta perspectiva, o constante aperfeiçoamento deste banco de dados possibilitará o emprego 
das informações como ferramentas que possam auxiliar os gestores públicos a planejar e entender a atividade turística na região de fronteira.

\section{REFERÊNCIAS}

BARBOSA, L. G. M. Os impactos econômicos do turismo e sua implicação nas políticas públicas: o caso do município de Macaé-RJ, Brasil. In: VII CONGRESO INTERNACIONAL DEL CLAD SOBRE LA REFORMA DEL ESTADO Y DE LA ADMINISTRACIÓN PÚBLICA. Lisboa, Portugal. Out. 2002. Disponível em: <http://unpan1.un.org/intradoc/groups/public/documents/CLAD/clad0044545.pdf>. Acesso em: 06/12/2013.

BARBETTA, P. A. Estatística: Aplicada às Ciências Sociais. 4. ed. Florianópolis/SC: Editora da UFSC, 2001.

BARBOSA, L. G. M.; MARTElOtTE, M. C.; ZOUAIN, D. M. Os impactos econômicos do turismo no município do Rio de Janeiro e suas implicações no desenvolvimento local. In: Revista Acadêmica Observatório de Inovação do Turismo, v. I, n. 2, nov. 2006. Disponível em:

<http://bibliotecadigital.fgv.br/ojs/index.php/oit/article/viewFile/5613/4334>. Acesso em: 05/12/2013.

BORATTI, J. V.; ROCHA, J. M. Desenvolvimento e turismo sustentável: (re) definindo conceitos e estigmas. In: Revista \& Debate, Lajeado, v. 15, n. 1, 2008. Disponível em: $<$ https://www.univates.br/files/files/univates/editora/arquivos_pdf/estudo_debate/v15_n 1_2008/1_Desenvolvimento.pdf >. Acesso em: 06/12/2013.

BRASIL. Grupo de Trabalho Interfederativo de Integração Fronteiriça. Bases para uma Proposta de Desenvolvimento e Integração da Faixa de Fronteira. GTI: 2010. Disponível em:

<http://www.integracao.gov.br/c/document_library/get_file?uuid=ab3fdf20-dcf6-43e19e64-d6248ebd1353\&groupId=10157>. Acesso em: 04/08/2013.

Ministério do Turismo. Secretaria Nacional de Políticas de Turismo. Segmentação do Turismo. Marcos Conceituais. Brasília: Ministério do Turismo, 2006.

BRASIL. Decreto n 8.175, de 27 de dezembro de 2013. Dispõe sobre a alteração do Decreto $\mathrm{n}^{\mathrm{o}}$ 6.306, de 14 de dezembro de 2007, que regulamenta o Imposto sobre Operações de Crédito, Câmbio e Seguro, ou relativas a Títulos ou Valores Mobiliários IOF. Disponível em: <http://www.jusbrasil.com.br/diarios/64483777/dou-edicao-extrasecao-1-27-12-2013-pg-1>. Acesso em: 23/01/2014.

CARPES, A. Fichas para MARC [mensagem pessoal]. Mensagem recebida por <patydouras@gmail.com>em 11/12/13. 
CÁMARA DE INDUSTRIA Y COMERCIO - Informativo Black Friday 2013. Pedro Juan Caballero - PY: Cámara de Industria y Comercio, 2013. Panfleto promocional desdobrável, em tamanho $21 \mathrm{~cm}$ x $29,7 \mathrm{~cm}$.

COOPER, C.; FLETCHER, J.; FYALL, A.; GILBERT, D.; WANHILL, S. Turismo princípios e práticas. 2 ed. São Paulo: Bookman, 2001.

CUNHA, L. A Definição e o Âmbito do Turismo: um aprofundamento necessário. 2010. Disponível em:

<http://recil.grupolusofona.pt/bitstream/handle/10437/665/A\%20Defini\%C3\%83\%C2\% A7\%C3\%83\%C2\%A3o\%20e\%20o\%20\%C3\%83\%E2\%80\%9Ambito\%20do\%20Turis mo.pdf?sequence=1> Acesso em: 09/12/2013.

DENCKER, A. F. M. Métodos e técnicas de pesquisa em turismo. São Paulo: Futura, 2000.

INSTITUTO BRASILEIRO DE GEOGRAFIA E ESTATÍSTICA - IBGE - 1. Cidades - Infográficos: dados gerais do município. 2013. Disponível em: $<$ http://cidades.ibge.gov.br/xtras/perfil.php?codmun=500660>. Acesso em: 29/11/13.

INSTITUTO BRASILEIRO DE GEOGRAFIA E ESTATÍSTICA - IBGE - 2. Censo demográfico 2010. Disponível em:

<ftp://ftp.ibge.gov.br/Censos/Censo_Demografico_2010/Resultados_do_Universo/Resu ltados_preliminares_sobre_Rendimentos/tabelas_pdf/tab1_8_10.pdf $>$. Acesso em: 29/11/13.

LAGE, B. H. G; MILONE, P. C. Fundamentos multidisciplinares do turismo: economia do turismo. In: TRIGO, L. G. G. Turismo: como aprender, como ensinar. V. 1. São Paulo: SENAC, 2000.

Economia do turismo. Campinas, SP: Papirus, 1992.

LAMBERTI, E.; MARTINS, P. C. S.; OLIVEIRA, T. C. M. Aspectos urbanos e socioeconômicos em região de fronteira: o caso de Ponta Porã/ MS. Julho 2006. Disponível em:

<http://www.sbpcnet.org.br/livro/58ra/senior/RESUMOS/resumo_184.html>. Acesso em: 29/11/13.

LEMOS, L. O valor turístico na economia da sustentabilidade. São Paulo: Aleph, 2005.

MARTINS, P. C. S. A formação do território turístico de Pedro Juan Caballero (Paraguai). Aquidauana: UFMS, 2007.

MINISTERIO DE ASUNTOS EXTERIORES. Oficina de información diplomática República del Paraguay. Set. 2013. Disponível em:

<http://www.exteriores.gob.es/Documents/FichasPais/Paraguay_FICHA\%20PAIS.pdf>. Acesso em: 29/11/13. 
NASCIMENTO, A. M. V.; ROCHA, L. K. S.; DE AZEVEDO, F. F.; MORAIS, I. R. D. Turismo e Transformações Socioespaciais: uma aproximação teórica e conceitual. Turismo e Sociedade, v. 6, n. 2., 2013, p. 388-407. Disponível em: <http://ojs.c3sl.ufpr.br/ojs/index.php/turismo/article/view/31933>. Acesso em: 24/01/2014.

OLIVEIRA, T. C. M. de (coord.) Perspectivas para o meio ambiente urbano: GEO Ponta Porã. Mato Grosso do Sul, Campo Grande: [s. n.], 2010. Disponível em: <http://www.pnuma.org.br/admin/publicacoes/texto/geo_ponta_pora.pdf >. Acesso em: 04/08/2013.

OMT. Organização Mundial do Turismo. Introdução ao Turismo. São Paulo. Roca, 2001.

PANOSSO NETTO, A.; ANSARAH, M. G. R. Segmentação em turismo: Panorama atual. In: PANOSSO NETTO, A.; ANSARAH, M. G. R. (Eds.) Segmentação do mercado turístico: estudos, produtos e perspectivas. Barueri-SP: Manole, 2009, p. 1943.

PNUD. PROGRAMA DAS NAÇÕES UNIDAS PARA DESENVOLVIMENTO. Relatório do Desenvolvimento Humano 2011 - Anexo estatístico do desenvolvimento humano. Disponível em: <http://hdr.undp.org/en/media/HDR_2011_PT_Tables.pdf>. Acesso em: 29/11/13.

PREFEITURA MUNICIPAL DE PONTA PORÃ. Perfil socioeconômico da fronteira Ponta Porã (Brasil) Pedro Juan Caballero (Paraguai). Ponta Porã, 2013.

RABAHY, W. A. Turismo e desenvolvimento: estudos econômicos e estatísticos no planejamento. São Paulo: Manole, 2003.

Fundamentos econômicos e quantitativos no planejamento turístico. Revista Turismo em Análise, v. 1, n. 1. São Paulo: Universidade de São Paulo - USP. 1990. Disponível em: <http://www.revistas.usp.br/rta/article/view/63855>. Acesso em: 16 jan. 2014.

RUSCHMANN, D. V. M. Turismo e planejamento sustentável. 8. ed. Campinas / SP: Papirus, 2001.

SEBRAE. SERVIÇO BRASILEIRO DE APOIO ÀS MICRO E PEQUENAS EMPRESAS. Mato Grosso do Sul sem fronteiras - núcleo de atendimento integrado. 2013. Disponível em:

$<$ http://semfronteiras.ms.sebrae.com.br/portal/?page=channel\&id=33>. Acesso em: 20/11/13.

TRIBE, J. M. Economia do lazer e do turismo. 1. ed. São Paulo: Manole, 2003. 
VAZ, G. N. Marketing turístico: receptivo e emissivo: um roteiro estratégico para projetos mercadológicos públicos e privados. São Paulo: Pioneira, 1999.

VERBEKE-JANSE, M. A sinergia entre compras e turismo. In: THEBALD, W. (org). Turismo Global. 3. ed. São Paulo: Editora SENAC São Paulo, 2002.

Recebido em: 11-03-2014.

Aprovado em: 10-04-2014. 